\title{
IL-21-Driven Neoplasms in SJL Mice Mimic Some Key Features of Human Angioimmunoblastic T-Cell Lymphoma
}

Shweta Jain, ${ }^{*}$ Jing Chen, ${ }^{\dagger}$ Alina Nicolae, ${ }^{\ddagger}$ Hongsheng Wang, ${ }^{*}$ Dong-Mi Shin, ${ }^{\S}$ Elisabeth B. Adkins, ${ }^{\top \|}$ Thomas J. Sproule, ${ }^{\natural}$ Caroline M. Leeth, ${ }^{* *}$ Tomomi Sakai, ${ }^{*}$ Alexander L. Kovalchuk, ${ }^{*}$ Mark Raffeld, Jerrold M. Ward, ${ }^{\star}$ Jerold E. Rehg, ${ }^{\dagger \dagger}$ Thomas A. Waldmann, ${ }^{\dagger}$ Elaine S. Jaffe, ${ }^{\dagger}$ Derry C. Roopenian, ${ }^{\mathrm{T} \|}$ and Herbert C. Morse, III*

From the Virology and Cellular Immunology Section,* Laboratory of Immunogenetics, National Institute of Allergy and Infectious Diseases, Rockville, Maryland; the Lymphoid Malignancies Branch ${ }^{\dagger}$ and the Laboratory of Pathology, ${ }^{\ddagger}$ Center for Cancer Research, National Cancer Institute, National Institutes of Health, Bethesda, Maryland; the Department of Food and Nutrition, ${ }^{\S}$ Seoul National University, Seoul, Republic of Korea; the Jackson Laboratory, ${ }^{\Uparrow}$ Bar Harbor, Maine; the Genetics Program," Tufts University Sackler School of Graduate Biomedical Sciences, Boston, Massachusetts; the Department of Animal and Poultry Sciences, ** College of Agriculture and Life Sciences, Virginia Polytechnic Institute and State University, Blacksburg, Virginia; and the Department of Pathology ${ }^{\dagger \dagger}$ St. Jude Children's Research Hospital, Memphis, Tennessee

Accepted for publication July 30, 2015.

Address correspondence to Herbert C. Morse III, M.D., Virology and Cellular Immunology Section, Laboratory of Immunogenetics, National Institute of Allergy and Infectious Diseases, NIH, Room 1421, Twinbrook Building 1, MSC-8152, 5640 Fishers Lane, Rockville, MD 20852. E-mail: hmorse@niaid.nih.gov.

\begin{abstract}
$\mathrm{SJL} / \mathrm{J}$ mice exhibit a high incidence of mature B-cell lymphomas that require $\mathrm{CD}^{+}{ }^{+} \mathrm{T}$ cells for their development. We found that their spleens and lymph nodes contained increased numbers of germinal centers and $T$ follicular helper $\left(\mathrm{T}_{\mathrm{FH}}\right)$ cells. Microarray analyses revealed high levels of transcripts encoding IL-21 associated with high levels of serum IL-21. We developed IL-21 receptor (IL21R)-deficient Swiss Jim Lambart (SJL) mice to determine the role of IL-21 in disease. These mice had reduced numbers of $T_{F H}$ cells, lower serum levels of IL-21, and few germinal center B cells, and they did not develop B-cell tumors, suggesting IL-21-dependent B-cell lymphomagenesis. We also noted a series of features common to SJL disease and human angioimmunoblastic T-cell lymphoma (AITL), a malignancy of $\mathrm{T}_{\mathrm{FH}}$ cells. Gene expression analyses of AITL showed that essentially all cases expressed elevated levels of transcripts for IL21, IL21R, and a series of genes associated with $T_{F H}$ cell development and function. These results identify a mouse model with features of AITL and suggest that patients with the disease might benefit from therapeutic interventions that interrupt IL-21 signaling. (Am J Pathol 2015, 185: 3102-3114; http://dx.doi.org/10.1016/j.ajpath.2015.07.021)
\end{abstract}

The Swiss Jim Lambart (SJL) mouse has been studied as a model of a lymphoproliferative disease progressing to malignant lymphomas for $>50$ years. The lymphoid proliferations are polymorphous and heterogeneous, prompting a comparison to Hodgkin lymphoma in the older literature. ${ }^{1}$ Recently, it has been recognized that SJL mice spontaneously develop clonal or oligoclonal B-cell non-Hodgkin lymphomas., However, the mechanisms involved in tumorigenesis have not been well defined.

Previous studies by Thorbecke and coworkers ${ }^{4,5}$ suggested a paradigm for SJL disease that they termed reverse immune surveillance. This model indicated that $\mathrm{CD} 4^{+} \mathrm{T}$ cells expressing a specific T-cell receptor $\beta$ chain (Tcrb) variable region proliferated when presented with a viral superantigen (vSag) encoded by the mammary tumor virus, $M t v 29$. In response, the activated T cells also produced cytokines that drove B-cell proliferation and, eventually, transformation.

Our current studies were directed at deciphering the pathogenesis of the B-cell lymphoproliferative process in

Supported, in part, by the Intramural Research Program of the NIH, the National Institute of Allergy and Infectious Diseases (H.C.M., H.W., A.L.K., S.J., T.S., D.-M.S., and J.M.W.), and the National Cancer Institute (J.C., E.S.J., A.N., and T.A.W.), in part by the Alliance for Lupus Research (D.C.R.) and the Lakeside Foundation (D.C.R.), and in part by Seoul National University (D.-M.S.). C.M.L. was supported in part by an NIH training grant. E.B.A. was supported by The Jackson Laboratory's Education Program.

S.J., J.C., A.N., H.W., and D-M.S. contributed equally to this work.

Disclosures: None declared.

Current address of D-M.S., Department of Food and Nutrition, Seoul National University, Seoul, Republic of Korea. 
the context of the reverse immune surveillance model. We found that SJL mice progressively developed many $\mathrm{CD} 4^{+} \mathrm{T}$ follicular helper $\left(\mathrm{T}_{\mathrm{FH}}\right)$ cells that have been shown to promote normal B-cell maturation, germinal center (GC) formation, and memory and plasma cell differentiation by producing their signature cytokine, IL-21. ${ }^{6,7}$ Consistent with this, SJL mice develop high levels of $I l 21$ transcripts and circulating IL-21 protein, as well as increased GC B cells and plasma cells. We examined the importance of IL-21 signaling to development of disease by generating SJL mice homozygous for a null mutation of the gene encoding the $\mathrm{IL}-21$ receptor, Il21r. IL$21 \mathrm{R}$-deficient mice $<12$ months had lower frequencies of $\mathrm{T}_{\mathrm{FH}}$, did not develop GC, had lower levels of serum IL-21, and did not develop B-cell malignancies. From this, we conclude that IL-21 signaling is critical to the development of SJL disease. More important, however, some IL21R-deficient SJL mice developed late T-cell lymphomas.

During the course of these studies, we recognized that SJL disease shares several features with human angioimmunoblastic T-cell lymphoma (AITL), a malignancy of $\mathrm{T}_{\mathrm{FH}} \cdot{ }^{8}$ These include presentation with advanced disease, generalized lymphadenopathy, hypergammaglobulinemia, diverse histological patterns, frequent clonal populations of B cells, and plasmacytosis. In addition, although elevated expression of IL-21 has been noted in studies of gene expression profiling in AITL, ${ }^{9,10}$ prior studies have not emphasized the potential significance of IL-21 to the human disease. The prognosis for patients with AITL is poor, with 5-year survival of only 33\% in one large international study. ${ }^{8,11}$ Optimal management of the disease is yet to be defined. Our studies suggest that SJL mice provide a model for some aspects of AITL and that interventions directed at interrupting the IL-21 signaling pathway might greatly benefit patients with this disease.

\section{Materials and Methods}

Mice

SJL/J, SWR/J, and C57BL/6J (B6) mice were obtained from The Jackson Laboratory (Bar Harbor, ME). Mice were bred and maintained in the laboratory of D.C.R. at The Jackson Laboratory or the laboratory of H.C.M. at the NIH (Bethesda, MD). NFS.V $\mathrm{V}^{+}$mice $^{12}$ were maintained at the NIH. SJL mice deficient in expression of IL-21R, designated SJL.129 Il21rtmlWlj $\left(\mathrm{Il} 21 \mathrm{r}^{-/-}\right)$, were bred by serially backcrossing $1 / 21 \mathrm{rtm} 1 \mathrm{Wjl}$ mice ${ }^{13}$ to SJL/J mice for 12 generations. Oligonucleotide primer sequences used for genotyping to detect the wild-type (WT) band of mouse IL-21R were as follows: forward, $5^{\prime}$-CATTTCCAAAGAGCTCCAGTAAACAG-3'; and reverse, $5^{\prime}$-CTTGGCCTGCAGTTCTGACG- $3^{\prime}$. These primers were used in combination with standard neo primers. Early studies showed that some $I l 21 r^{-1-}$ mice $>5$ months developed pneumonia caused by infection with Pneumocystis murina. As a result, this colony and control SJL mice were maintained on drinking water containing trimethoprim-sulfamethoxazole. No histological evidence of infection was observed in any treated mice. Only female SJL mice were used in these studies because males become aggressive and require separate caging of pairs or individual mice. All animal studies were performed under protocols approved by the Animal Care and Use Committees of The Jackson Laboratory (01022) or the NIH (Laboratory of Immunogenetics 16).

\section{Measurements of Serum Ig and Cytokine Levels}

Serum Ig and IL-21 cytokine levels were estimated by standard sandwich enzyme-linked immunosorbent assay methods. Briefly, serum dilutions were added on plates coated with purified anti-mouse IgG2b antibodies (BD Biosciences, San Jose, CA) or purified anti-mouse IL-21 antibody (Peprotech, Rocky Hill, NJ). Bound IgG2b or IL-21 was captured by secondary biotinylated anti-mouse IgG2b (BD Biosciences) or IL-21 (Peprotech), respectively, followed by avidin-horseradish peroxidase (Sigma, St. Louis, MO) $/ 3,3^{\prime}, 5,5^{\prime}$ tetramethylbenzidine (Invitrogen, Carlsbad, CA) for colorimetric estimation. Standard washing steps with phosphate-buffered salineTween-20 $(0.05 \%)$ were followed during each step. Results were computed as concentration of $\operatorname{IgG} 2 \mathrm{~b}$ or IL-21 in serum with respect to serial dilutions $\left(\log _{2}\right)$ of standard purified mouse IgG2b (BD Biosciences) or IL-21 (Peprotech) used for plotting reference curves.

\section{Gene Expression Profiling}

Total RNA prepared from spleen cells of female SJL mice of different ages and normal NFS. $\mathrm{V}^{+}$mice were applied to Agilent (Santa Clara, CA) National Institute of Allergy and Infectious Diseases-customized mouse gene expression arrays with scanned images analyzed as detailed previously. ${ }^{14}$ Raw data were normalized with LIMMA package software version 2.9.17 in R software version 2.4.1 (http://www.r-project.org, last accessed September 13, 2013). Differentially expressed genes were identified with one-way analysis of variance analysis with $5 \%$ false-discovery rate. The microarray data are deposited in National Center for Biotechnology Information's Gene Expression Omnibus (http://www.ncbi.nlm.nih.gov/geo; accession number GSE57150).

\section{Tumor Transplantation}

Single-cell suspensions prepared from spleens of old SJL mice with splenomegaly were injected i.v. into young SJL WT mice $\left(2 \times 10^{6}\right.$ cells per mouse). Recipients were necropsied when spleens reached approximately $500 \mathrm{mg}$ by palpation. Some transplanted tumors were serially passaged using the same protocol.

\section{Sequencing R3ch1 cDNA}

mRNA obtained from spleens of three young SJL mice was converted to cDNA and tested for the Sanroque T- $>$ G mutation 
Table 1 Antibodies for FACS and IHC Analysis

\begin{tabular}{|c|c|c|c|c|}
\hline Antibodies & Clone & $\begin{array}{l}\text { Type of } \\
\text { analysis }\end{array}$ & Fluorochrome & Source \\
\hline CD4 & GK1.5 & FACS & FITC, PE, PB, Percp.Cy5.5 & Biolegend (San Diego, CA) \\
\hline CD4 & GK1.5 & FACS & APC.Cy7 & BD Biosciences (San Jose, CA) \\
\hline CD8 & $53-6.7$ & FACS, IHC & Biotin, FITC, PE, PB & BD Biosciences \\
\hline $\mathrm{CD} 11 \mathrm{~b}$ & $\mathrm{M} 1 / 70$ & FACS & Biotin, Alexa Fluor 700/647 & BD Biosciences or Biolegend \\
\hline CD11c & HL3 & FACS & Purified, PE, PE.Cy7 & BD Biosciences \\
\hline CD19 & ID3 & FACS & Biotin, FITC, PE, APC, Percp.Cy5.5 & BD Biosciences \\
\hline ICOS & C $398.4 \mathrm{~A}$ & FACS & PE.Cy5 & eBioscience (San Diego, CA) \\
\hline PD-1 & $29 F .1 A 12$ & FACS & APC & Biolegend \\
\hline CD122 & $\mathrm{TM}-\beta 1$ & FACS & PE & BD Biosciences \\
\hline CD16/CD32 & $2.4 \mathrm{G} 2$ & FACS & & BD Biosciences \\
\hline $\mathrm{CD} 62 \mathrm{~L}$ & MEL-14 & FACS & PE & BD Biosciences \\
\hline B220 & RA3-6B2 & FACS, IHC & $\begin{array}{l}\text { FITC, PE, APC, PB, APC.Cy7, Alexa } \\
\text { Fluor 700, biotin, Qdot } 655\end{array}$ & BD Biosciences or Invitrogen (Carlsbad, CA) \\
\hline CXCR5 & L138D7 & FACS & PE, PerCP.Cy5.5 & Biolegend \\
\hline CD44 & IM7 & FACS & FITC, Alexa Fluor 700 & BD Biosciences \\
\hline CD138 & $281-2$ & FACS, IHC & Biotin, PE & Biolegend \\
\hline Gr-1 & $\mathrm{RB} 6-8 \mathrm{C} 5$ & FACS & PE.Cy7, PB, APC.Cy7, biotin & BD Biosciences \\
\hline CD95 & Jo2 & FACS & Biotin & BD Biosciences \\
\hline NKG2A & $16 a 11$ & FACS & Biotin & eBioscience \\
\hline Ly49 & 3D10 & FACS & APC & eBioscience \\
\hline DX5 & DX5 & FACS & PE.Cy7 & eBioscience \\
\hline GL7 & GL-7 & FACS & FITC & BD Biosciences \\
\hline PNA & & FACS & Biotin & Sigma-Aldrich (St. Louis, M0) \\
\hline PNA & & $\mathrm{IHC}$ & Biotin & Vector Labs (Burlingame, CA) \\
\hline
\end{tabular}

APC, allophycocyanin; FACS, fluorescence-activated cell sorter; FITC, fluorescein isothiocyanate; ICOS, inducible T cell costimulator; IHC, immunohistochemistry; PB, Pacific Blue; PD-1, programmed cell death protein 1; PE, phosphatidylethanolamine; PNA, peanut agglutinin.

in exon 5 of the $R 3 c h 1 n$ gene. ${ }^{15}$ Primers spanning exons 2 and 6 of the gene [exon 2, 5'-AATTTGCACTCAGACTTTCGAC-3' (forward); exon 6, 5'-TGAGACTGATCCCCATAAAGCA-3' (reverse)] were used in a 35 -cycle PCR with melting at $95^{\circ} \mathrm{C}$ for 30 seconds, annealing at $55^{\circ} \mathrm{C}$ for 30 seconds, and extension at $72^{\circ} \mathrm{C}$ for 1 minute. Resulting PCR products were subsequently cloned and sequenced. Sequences were aligned to the C57BL/6 reference genome using the University of California, Santa Cruz, genome browser.

\section{Mouse Histopathology and IHC}

Tissues obtained at necropsy were fixed in $10 \%$ neutralbuffered formalin and embedded in paraffin. Paraffin blocks from additional cases necropsied at 12 to 24 months of age as part of an aging SJL/J study were provided by Dr. John Sundberg (The Jackson Laboratory). Sections were stained with hematoxylin and eosin, and antibodies are listed in Table 1 with appropriate secondary antibodies and using the diaminobenzidine chromogen immunohistochemical (IHC) technique. Histology images were viewed with an Olympus BX41 microscope $(10 \times$ to $100 \times$ objectives) and photographed with an Olympus DP71 camera (both from Olympus, Waltham, MA). DP controller software version 3.3.1.292 was used for image acquisition. Histopathological diagnoses were made using established criteria. $^{16,17}$

\section{Flow Cytometry and Fluorescence-Activated Cell Sorting}

Single-cell suspensions were stained with conjugated antibodies listed in Table 1. Data were obtained on a BD LSRII (BD Biosciences) using established techniques and analyzed with FlowJo software version 10 (Tree Star, Ashland, OR).

\section{Molecular Analyses of the Tcrb Repertoire}

We performed an in-depth analysis of Tcrb rearrangements in DNA prepared from spleens of SJL, SJL.Il $21 r^{-/-}$, and SWR mice and tumor transplants from SJL mice. To examine the Tcrb repertoire, we used an approach developed by Adaptive Biotechnologies Corp. (Seattle, WA) that integrates multiplex PCR with high-throughput sequencing and advanced bioinformatics to characterize the $T c r b$ repertoire in a quantitative and unbiased manner, as described previously. ${ }^{18-20}$

\section{Human Tissues}

We studied formalin-fixed, paraffin-embedded lymph node biopsy specimens from 40 cases of AITL and blocks from 10 biopsy specimens of non-tumor-bearing lymph nodes obtained during surgical procedures for various cancers. The diagnosis of AITL was established on the basis of criteria of the World Health Organization classification, using a standard immunophenotypic and genotypic panel described 


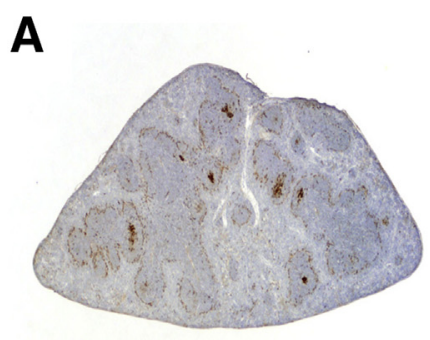

2 months

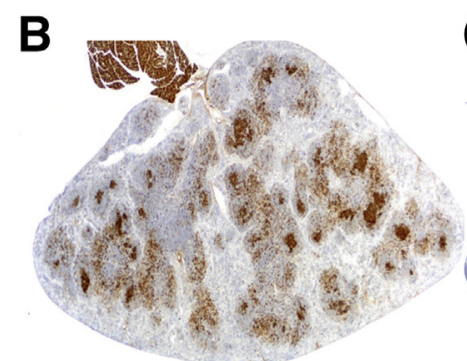

12 months

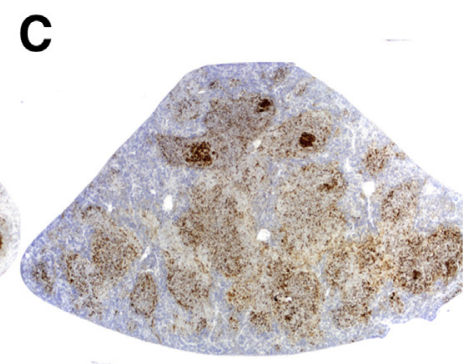

12 months

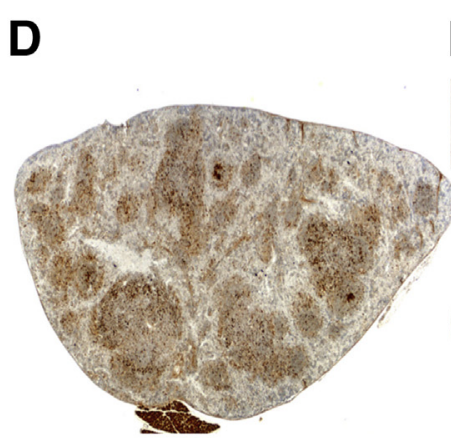

12 months
E

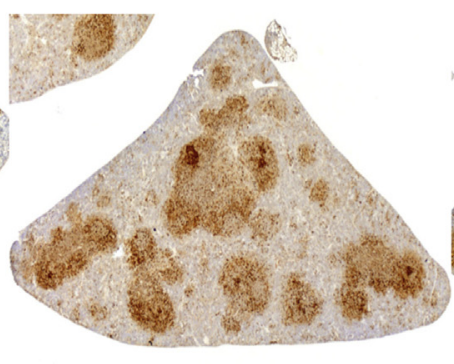

DLBCL-11 months
$\mathbf{F}$

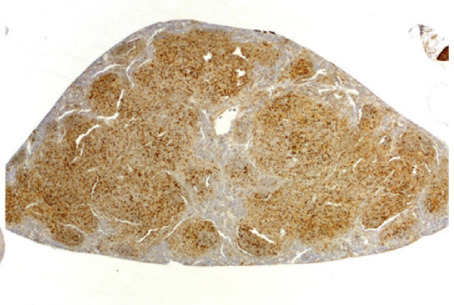

HS- 8 months
G

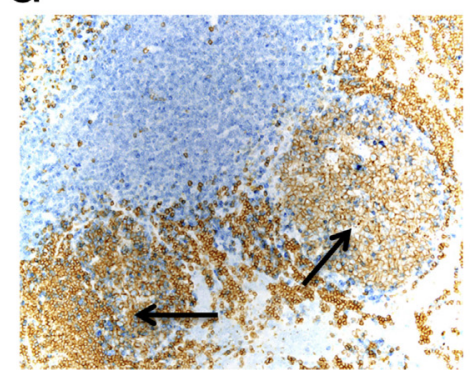

Figure 1 Comparative immunohistochemical analyses of young and old SJL mice. Spleen sections from young (A), old (B-D), and diseased ( $\mathbf{E}$ and $\mathbf{F}$ ) SJL mice were stained with peanut agglutinin to determine the germinal centers. G: Spleen section of a SJL mouse stained with CD3 (blue) and CD45R (B220; brown) to determine T-cell infiltration. Arrows indicate germinal centers. DLBCL, diffuse large B-cell lymphoma; HS, histiocytic sarcoma. previously. ${ }^{21}$ The neoplastic cells had $\mathrm{T}_{\mathrm{FH}}$ immunophenotype, were associated with expansion of follicular dendritic cell meshworks, and, in all cases, contained varying numbers of Epstein-Barr virus (EBV)-positive B cells (Supplemental Table S1).

Gene expression profiling was performed using NanoString technology (NanoString Technologies, Seattle, WA) to test RNA prepared from paraffin block sections using probes listed in Supplemental Table S2. The genes were chosen on the basis of known expression patterns in mouse and human $\mathrm{T}_{\mathrm{FH}}$ and both GC and post-GC B-cell subsets. The results were analyzed using two-way hierarchical clustering.

\section{Results}

Pleomorphic Neoplasms and Lymphoproliferation Characterize SJL Disease

In the present study, mice presented with splenomegaly and lymphadenopathy beginning at 7.5 months of age and were necropsied. Of 80 mice $>3$ months, 45 (56\%) were diagnosed with neoplasms, including 18 diffuse large B-cell lymphomas (DLBCLs), 21 plasmacytic or anaplastic plasmacytomas, and 6 histiocytic sarcomas using established criteria. ${ }^{16,17,22}$ The others were diagnosed as SJL disease, exhibiting the pleomorphic mixture of cell types described previously. ${ }^{15}$ Images of the different tumor types are presented in Figure 1.

To determine whether spleens of 1-year-old SJL mice contained malignant tumors as defined by transplantability, single-cell suspensions prepared from spleens of three mice were injected i.v. $\left(2 \times 10^{6}\right.$ cells $)$ into 5 - to 6-week-old SJL female mice. One of the donors was diagnosed with histiocyterich DLBCL and two with plasmacytomas. All recipients developed splenomegaly in 4 to 8 weeks after transfer. At necropsy, the recipients of cells from mice diagnosed with DLBCL or plasmacytoma were found to have the same tumor types as the donors. Spleen cells from spleens of two primary recipients were transplanted for a second time, leading to development of tumors that were histologically similar to those of the first-generation transplant tumors. A representative example of a primary tumor and the transplanted tumor in one recipient is shown in Supplemental Figure S1. 
A

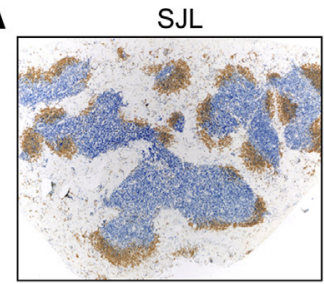

B

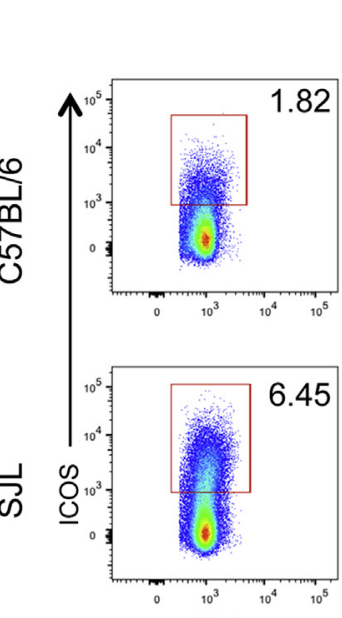

$\mathrm{T}_{\mathrm{FH}}$

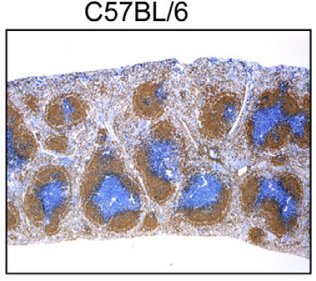

CD4
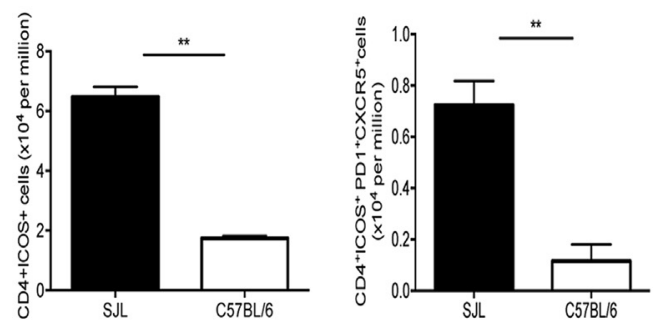

C
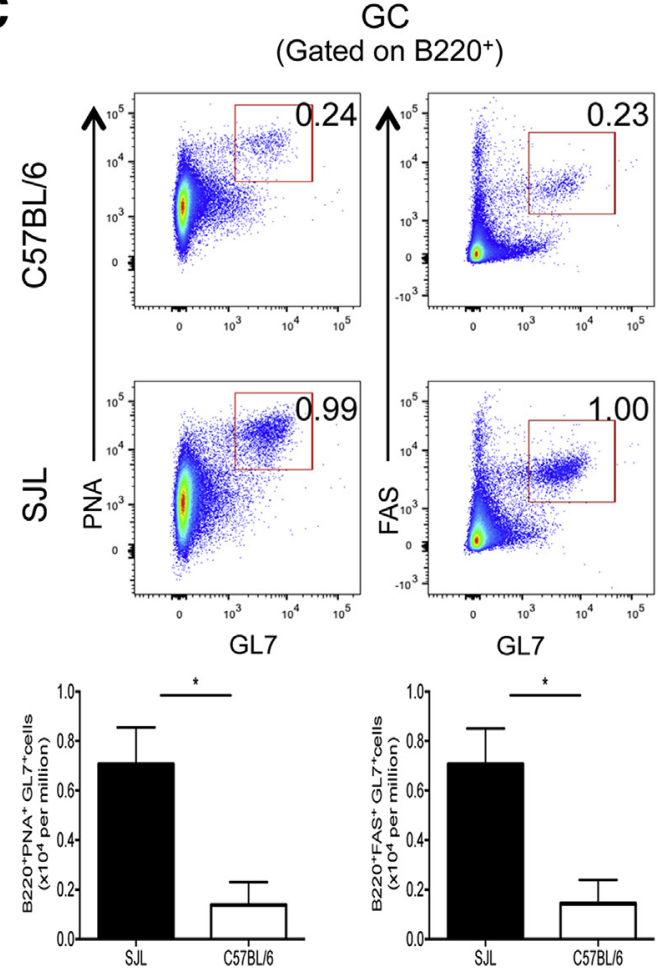

IHC and Fluorescence-Activated Cell Sorter Analyses Identify Major Changes in Follicular Structures and Cell Content

Studies of SJL mice 2 to 24 months of age revealed agerelated, temporally uneven but progressive change in splenic and lymph node architecture, with peanut agglutinin (PNA) reactivity being particularly informative. In young mice with small spleens, follicular structure was relatively well preserved, with prominent PNA-positive GC in some follicles (Figure 1A). Marginal zone macrophages were clearly positive, but PNA reactivity outside GC in follicles was minimal. In contrast, the spleens of 12-month-old mice were uniformly enlarged but variable for PNA reactivity. All had an expanded white pulp, some with many follicles containing prominent $\mathrm{PNA}^{+} \mathrm{GCs}$ of varying size and showing PNA reactivity with many non-GC-associated follicular cells (Figure 1B). Finally, some spleens with greatly altered architecture had enlarged follicles containing few, if any, GCs but many PNAreactive follicular cells (Figure 1, C and D). Furthermore, IHC analyses revealed greatly enlarged splenic follicles compressing the red pulp in aged mice (Figure 1D) and in mice diagnosed with DLBCL or histiocytic sarcoma (Figure 1, E and $\mathrm{F}$ ), with $\mathrm{CD}^{+} \mathrm{T}$ cells populating expanded periarteriolar lymphoid sheaths (Figure 1G).

Fluorescence-activated cell sorter analyses showed that the frequencies of cells with a $\mathrm{T}_{\mathrm{FH}}$ phenotype $\left(\mathrm{CD} 4^{+} \mathrm{CXCR} 5^{+}\right.$ $\mathrm{ICOS}^{+} \mathrm{PD}-1^{+}$) were significantly higher in spleens of SJL than normal C57BL/6 mice (Figure 2B). In keeping with the IHC analyses, the frequencies of $\mathrm{FAS}^{+} \mathrm{GL}^{-}{ }^{+} \mathrm{GC} \mathrm{B}$ cells were also markedly higher in spleens and lymph nodes of young mice (data not shown) (Figure 2C). We found that SJL disease in prelymphomatous mice features marked expansions of $\mathrm{T}$ cells, including the $\mathrm{CD}^{+} \mathrm{T}_{\mathrm{FH}}$ subset, and large active GC. This is followed by major changes in splenic and lymph node architecture, marked in many mice by a progressive loss of GC followed by tumor development (Figure 2A).

\section{Microarray-Based Gene Expression Profiling}

To identify genes that might contribute to the pathogenesis of SJL disease, we compared the gene expression profiles of spleens from SJL mice that were 6 weeks, 6 months, and 12 months of age with those of spleens from young, healthy NFS.V $\mathrm{V}^{+}$mice that also develop a high incidence of B-cell lineage lymphomas, but only in older mice. ${ }^{12}$ A principal component analysis of the four

Figure 2 SJL mice have increased proportions of $\mathrm{CD}^{+} \mathrm{T}$ follicular helper and germinal center (GC) B cells. A: Spleen sections from SJL and C57BL/6 mice were double stained with $\operatorname{CD} 3$ (blue) and CD45R (B220; brown) to show the follicles. Spleen cells from 3-month-old SJL mice and C57BL/6 mice (control) were stained with antibodies against CD4, ICOS, CXCR5, and PD-1 (CD4 $\left.{ }^{+} \mathrm{T}_{\mathrm{FH}}\right)(\mathrm{B})$ and B220, GL-7, and FAS (C) (GC B cells) and analyzed by flow cytometry. Numbers indicate percentage of total cells. Data indicate means \pm SEM (B and C). $n=4$ individual animals (B and C). ${ }^{*} P<0.05,{ }^{*} P<0.01$ (two-tailed unpaired $t$-test). Original magnification, $\times 40$ (A). FAS, CD95 or apoptosis antigen $1 ; \mathrm{GL}-7, \mathrm{~B}$ and $\mathrm{T}$ cell activation antigen; ICOS, inducible $\mathrm{T}$ cell costimulator; PD-1, programmed cell death protein 1; PNA, peanut agglutinin. 

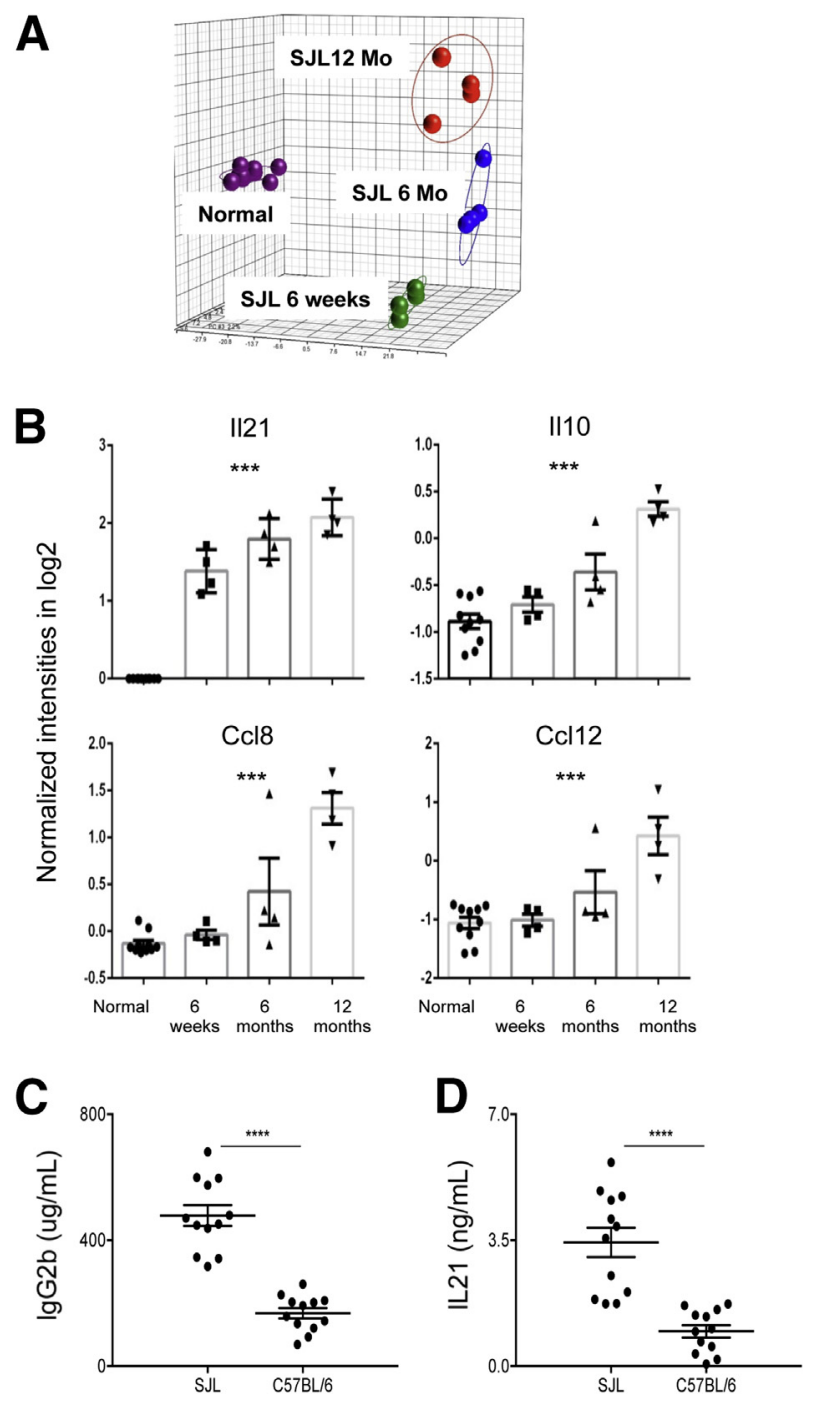

Figure 3 SJL mice have differentially up-regulated expression of Il21 transcripts. RNA prepared from spleens of cohorts of SJL mice 6 weeks, 6 months (Mo), and 12 months of age and young, normal NFS. $V^{+}$mice was used for transcriptome analyses using Agilent customized arrays. A: Principal component analysis and analysis of variance analysis was used to identify differentially expressed genes. B: Transcript levels of significant cytokines and chemokines among different age groups are shown with respect to NFS. $\mathrm{V}^{+}$ mice as reference. Bars represent normalized intensities. C and D: Sera from SJL and C57BL/6 were quantified for IgG2b (C) and IL-21 (D) by sandwich enzyme-linked immunosorbent assay. Data are expressed as means \pm SEM (B-D). $n=4$ biological replicates at each age and 10 controls (B); $n=12$ (C and D, SJL and C57BL/6). ${ }^{* *} P<0.001,{ }^{* * * *} P<0.0001$ [one-way analysis of variance analysis (B) and two-tailed unpaired $t$-test (C and $\mathbf{D})$ ].

groups showed that they fell into distinct nonoverlapping clusters, with each of the SJL groups being more closely related to one another than to the controls (Figure 3A).

A one-way analysis of variance analysis of the four groups (false-discovery rate, $<0.05$ ) was used to identify differentially expressed genes with a twofold change restriction in the comparisons of each SJL age versus normal NFS; this analysis yielded 113 genes (Supplemental Table S3). There was a striking age-related progressive up-regulation of transcript levels of Il21 (Figure 3B), the gene encoding IL-21, the signature cytokine of $\mathrm{T}_{\mathrm{FH}} \cdot{ }^{6,7}$ Interestingly, a parallel, but less striking, increase was seen for $I l 10$ transcripts from the gene encoding the cytokine IL-10 (Figure 3B). Among its multiple effects, IL-10 promotes the expansion of B cells activated by B-cell reactivity and costimulatory signals while also inhibiting antibody responses by negatively regulating $\mathrm{T}_{\mathrm{FH}}$ cells. ${ }^{23}$ Also, transcript levels for Rgs 13, which is expressed exclusively by GC B cells and mast cells, ${ }^{24,25}$ were consistently elevated in samples from SJL mice of all ages (Supplemental Table S3). Finally, transcripts for $\mathrm{Ccl}$ and $\mathrm{Ccl12}$, chemokines that act as chemoattractants for monocytes, eosinophils, basophils, and lymphocytes, were expressed at increasing levels with age (Figure 3B). Heightened expression of these chemokines may contribute to the polymorphic mixture of cell types found associated with SJL lymphomas and SJL disease.

In keeping with the increased levels of $\mathrm{T}_{\mathrm{FH}}$ in spleens and lymph nodes of SJL mice and the high levels of Il21 transcripts, we found that there were high levels of $\operatorname{IgG} 2 \mathrm{~b}$ and IL-21 proteins in their sera (Figure 3, C and D).

\section{IL-21 Signaling Drives the Cellular Changes in SJL Mice}

The phenotypic features, gene expression profiles, and elevated levels of serum IL-21 in mice with SJL disease or lymphomas suggested that the development of B-cell disease and expanded populations of splenic white pulp $\mathrm{T}$ cells may be driven by IL-21 produced by an enlarged population of $\mathrm{T}_{\mathrm{FH}}$. We examined this possibility directly by introducing a null allele of $I l 21 r$ onto the SJL background.

We first compared levels of IgG2b and IL-21 in sera of WT and $I l 21 r^{-1-}$ mice at 6 months of age when the mice would not be developing lymphomas. Consistent with a role for IL-21 in signaling to B cells, $I 21 r^{-/-}$mice had significantly reduced levels of circulating IgG2b (Figure 4A). Moreover, they had markedly lower levels of serum IL-21 (Figure 4B), likely reflecting the importance of $\mathrm{IL}-21$ in promoting $\mathrm{T}_{\mathrm{FH}}$ differentiation. We next used flow cytometry to further understand how a failure to signal through the IL-21R would affect the features of splenic $\mathrm{T}$ and $\mathrm{B}$ cells in 3- to 12-month-old mice. There were significant reductions in the frequencies of total $\mathrm{CD} 4^{+} \mathrm{T}$ cells and $\mathrm{T}_{\mathrm{FH}}$ in older $I l 21 r^{-1-}$ mice (Figure 4, C and D). Analyses of B cells showed that the frequencies of GC B cells were significantly reduced in the $I l 21 r^{-1-}$ mice of all ages (Figure 4E). These differences are consistent with the changes seen in IHC analyses of spleens from SJL WT and $I l 21 r^{-1-}$ mice and the important role of IL-21 in GC formation and GC B-cell persistence. ${ }^{6,26}$

We then performed histological and IHC studies of tissues obtained at necropsy from 12-month-old $I l 21 r^{-1-}$ and WT mice. Spleen sections stained with antibodies to CD3 and CD45R showed that the spleens of $I 21 r^{-/-}$mice were smaller and had less prominent periarteriolar lymphoid sheaths containing $\mathrm{T}$ cells (Figure 5, A and B). Spleens stained with the antibody F4/80 (encoded by Emrl), which is specific for macrophage lineage cells, again revealed marked expansion of the follicles associated with pronounced compression of the red pulp in SJL WT mice 
A

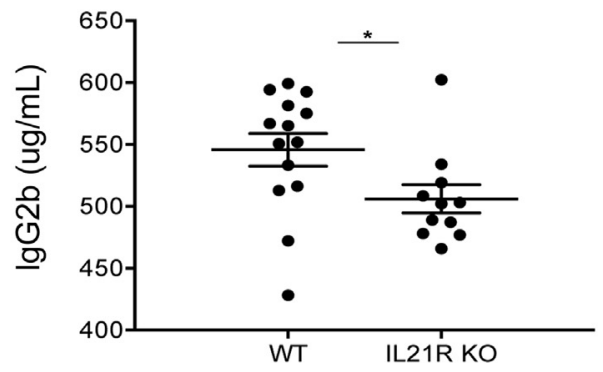

B

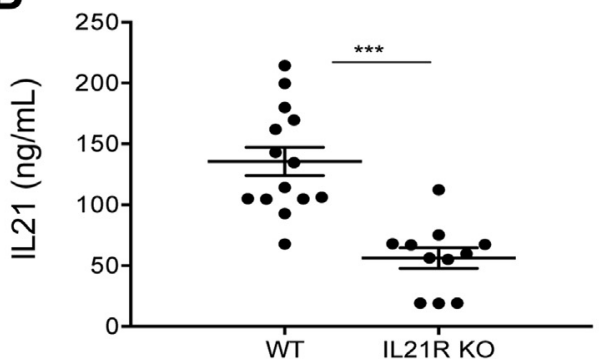

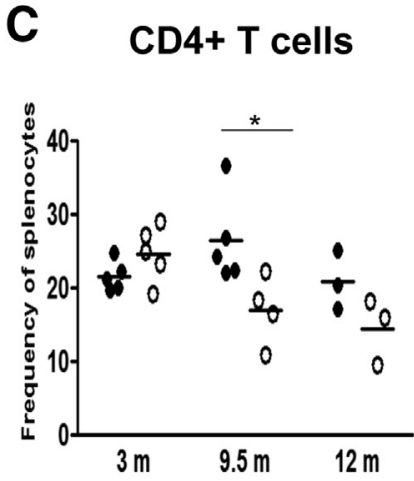

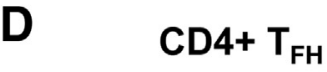

E GC B cells
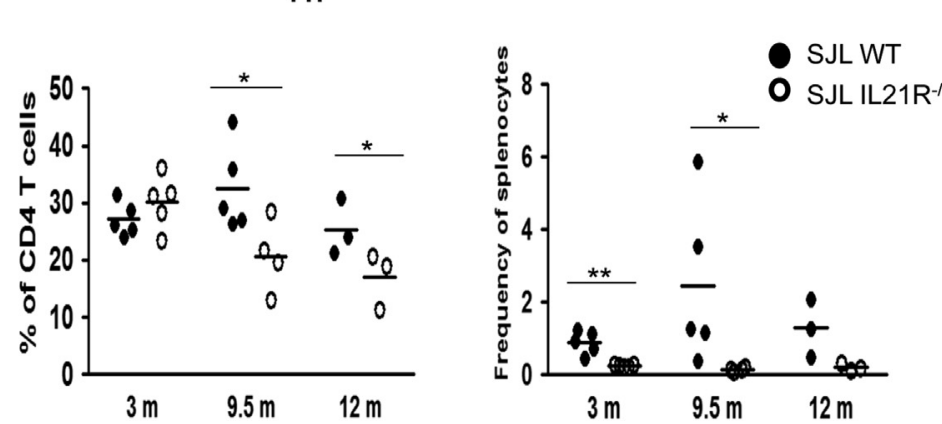

Figure 4 SJL IL21r ${ }^{-/-}$mice do not have hypergammaglobulinemia and have reduced levels of circulating IL-21. Sera from SJL wild-type (WT) mice (WT) and IL21r ${ }^{--}$mice [IL-21R knockout (KO)] were quantified for IgG2b (A) and IL-21 (B) by standard sandwich enzyme-linked immunosorbent assay. Data are represented as concentration of IgG2b or IL-21 calculated on the basis of standard reference curves and depicted as scatter plots for each group, where each dot represents one mouse. $P$ values were calculated using unpaired nonparametric $t$-test. Splenocytes from SJL WT mice and $I L 21 r^{-/-}$mice [12 months (m)] were stained with a panel of antibodies and analyzed by flow cytometry. Shown here are the total frequencies of $\mathrm{CD} 4^{+} \mathrm{T}$ cells $\left(\mathrm{CD} 4^{+} ; \mathrm{C}\right) \mathrm{CD}^{+} \mathrm{T}$ follicular helper

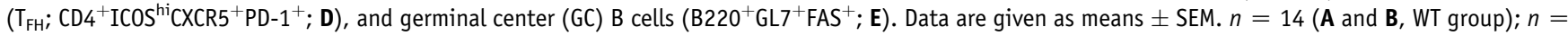
11 (A and $\mathbf{B}, \mathrm{KO}$ group); $n=3$ to 5 per group (C-E). ${ }^{*} P<0.05,{ }^{*} P<0.01$, and ${ }^{* * *} P<0.001$ (unpaired nonparametric $t$-test).

compared with a normal red pulp/white pulp ratio in the spleens of $I l 21 r^{-1-}$ mice (Figure 5, C and D). In the spleens and lymph nodes of SJL WT mice, PNA identified intensely stained GC cells in B-cell areas, a feature that was almost totally lacking in tissues of $I l 21 r^{-1-}$ mice (Figure 5, E and F). These results indicate that the interruption of IL-21R signaling in SJL mice resulted in reduced populations of $\mathrm{B}$ and $\mathrm{T}$ cells and a marked reduction in GC B cells.

No $I l 21 r^{-/-}$mice $<11$ months of age were diagnosed with lymphoid tumors, whereas a high proportion of WT mice had developed neoplasms beginning as early as 7.5 months of age (Table 2). However, three $I 121 r^{-/-}$mice that presented at 11 to 12 months of age with marked splenomegaly, lymphadenopathy, and enlarged thymus were diagnosed with lymphoblastic lymphomas. IHC analyses showed that all three tumors were $\mathrm{CD}^{+}$(Supplemental Figure S2). Taken together, these results demonstrated that interruption of the IL-21 signaling pathway markedly inhibited the development of many of the striking prototypic splenic abnormalities that accrue in SJL mice, yet with sporadic cases of T-cell lymphoblastic lymphoma developing at approximately 1 year of age. Our previous studies demonstrated that T-suppressor cells were responsible for slowing the progression of disease in SJL mice. ${ }^{27}$ Comparisons of $\mathrm{CD}^{+} \mathrm{CD}^{+} 2^{+} \mathrm{T}$-suppressor cells in spleens of WT and $I L 21 r^{-1-}$ mice showed that there were no significant differences in their frequencies at any age examined (data not shown).
Analyses for Clonal Cell Populations in SJL Tumors and SJL Disease

To investigate clonality, we sequenced $I g h$ and $T c r b$ chains from spleens of mice diagnosed with primary lymphomas or SJL disease as well as two transplant recipients of a single primary tumor. Remarkably, all sequenced $T c r b$ clones from different lymphomas and one case of SJL disease contained identical $\mathrm{V}$ gene sequences from a single Tcrbv3 family member (TCRVB3-01) but with different linked J gene sequences (Supplemental Table S4). For Igh sequences, a primary DLBCL and its two transplants all had the same sequence, Ighv36-60-J1-J4. A similar sequence was found in a mouse with SJL disease. Other sequences recovered from two additional primary DLBCLs were Igh-V 7183.20.37-DFL16.2J3-J4-Em-Cg1 and Igh-VJ606-J4-SEm-SM (Supplemental Table S4). Remarkably, all of the IgH amino acid sequences were heavily mutated with overall identities $<95 \%$.

Previous studies using Southern blot hybridization of DNA prepared from tissues of a low proportion of aged SJL.Fas ${ }^{\text {pr+t- }}$ mice revealed clonal rearrangements of the Tcrb locus suggestive of T-cell lymphomas ${ }^{28}$ but provided no information on TCR repertoire use. A critical element of the model of Thorbecke and Ponzio ${ }^{4}$ of SJL disease is that $\mathrm{CD}^{+} \mathrm{T}$ cells expressing TRVB3 TCRs (then termed V $\beta 10$ ) respond to the Mtv29-encoded vSag by producing cytokines that promote 


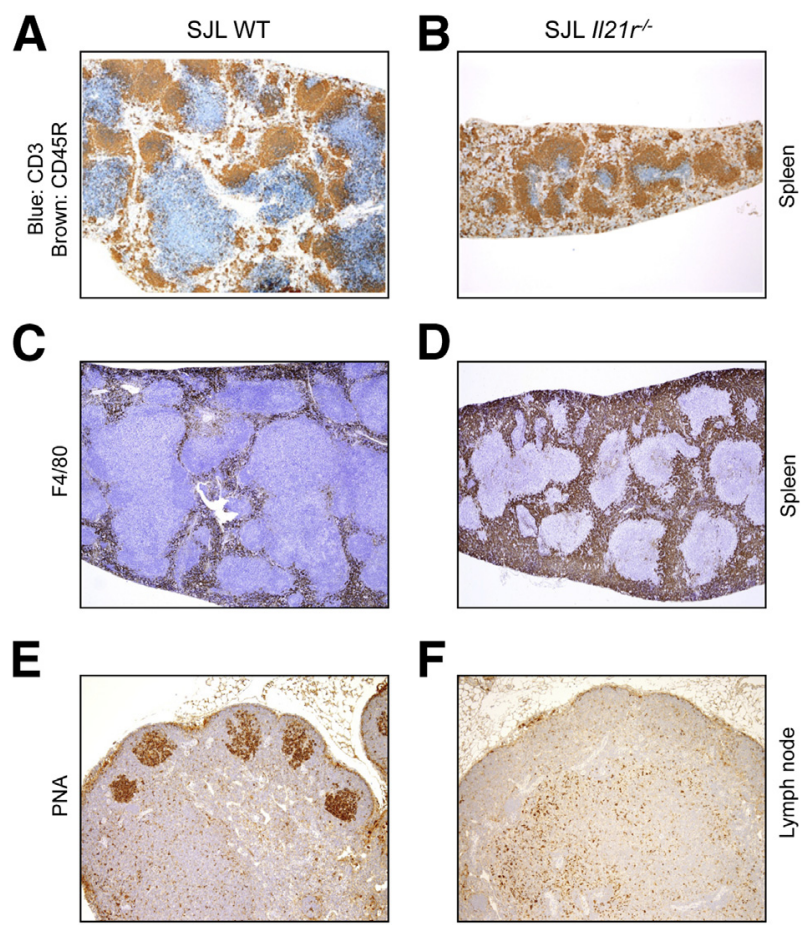

Figure 5 Comparative histological and immunohistochemical analysis of SJLIL21 ${ }^{-1-}$ mice and wild-type (WT) SJL mice. Data from 12-month-old SJL WT (A, C, and E) and SJL Il21 ${ }^{-/-}$mice (B, D, and F). A and B: Spleens double stained with antibodies to CD3 (blue) and CD45R (B220; brown) show much larger splenic white pulps in SJL WT mice. C and D: Spleens stained with antibody to $\mathrm{F} 4 / 80$, encoded by Emr1, to identify macrophage lineage cells show much larger $\mathrm{F} 4 / 80$-positive red pulps in $\mathrm{Il}_{21 r^{-/}}$mice. $\mathbf{E}$ and $\mathbf{F}$ : Lymph node sections were stained with peanut agglutinin (PNA). Note intense staining of germinal centers in B-cell areas in the cortex of SJL WT mice and their absence in $\mathrm{IL}_{21 \mathrm{r}^{-/-}}$mice. Original magnifications: $\times 40(\mathbf{A}$ and $\mathbf{B}) ; \times 100(\mathbf{C}-\mathbf{F})$.

chronic B-cell activation and, eventually, transformation. However, questions regarding the clonality of TCR use and the presence of T-cell tumors in these mice were not addressed.

Compared with the Tcrb locus of C57BL/6 and many other strains of mice, the SJL and SWR Tcrb loci lack an 80-kb region within the gene cluster encompassing Tbvb5.2 to Trbv9, ${ }^{29,30}$ making a comparison of SJL and SWR Tcrb repertoires valid. More important, SJL mice carry the Mtv29 mammary tumor virus genome encoding a vSag, whereas SWR mice do not. According to the model of Thorbecke and Ponzio ${ }^{4}$ of SJL disease, TRVB3-expressing CD4 ${ }^{+} \mathrm{T}$ cells will thus be activated in SJL, but not SWR, mice. To examine this hypothesis, we tested DNA prepared from primary tumors and tumor transplants from SJL mice, spleens of normal SWR/J mice, and spleens of $I l 21 r^{-1-} \mathrm{SJL}$ mice by combining a multiplex PCR with high-throughput sequencing and advanced bioinformatics to quantitatively characterize the $T c r b$ repertoire. We recovered a median of approximately $2.5 \times 10^{5}$ sequences per sample with a median of $>24,000$ unique sequences per sample. All samples were diverse, with few expanded clones and a median clonality of 0.046 . Further analyses by hierarchical clustering of the frequencies of $\mathrm{V} \beta$ genes identified in each sample are shown in the heat map in Figure 6. Most striking was the predicted increased representation of Trbv03-01 gene sequences in two of the three primary SJL tumors and both of the transplants from one primary tumor over those seen with the control SWR spleens (Figure 6). Interestingly, the use of this clone was substantially higher in the transplant (43237) than its primary tumor (43221). Also, the preferential use of TCRBV03-01 gene sequences seen in the primary spleens and tumor transplants was not seen in spleens of old SJL.Il21r ${ }^{-1-}$ mice (see Materials and Methods for description of these mice).

If high use of the TCRBV03-01 family was because of the presence of tumor populations of varying sizes in the different samples, we would expect to find multiple repeats of identical sequences. To test this hypothesis, we molecularly cloned two or three Trbv sequences from two different tumor transplants (43237 and 43238) from primary tumor 43221 (Figure 6) and an independent primary tumor, 43105 (Supplemental Table S5). All of the sequences were TRBV03-01 in origin, but differed in D/J use one from another, demonstrating that they did not derive from a monoclonal tumor. These results indicated that primary SJL tumors and their transplants regularly exhibited heightened use of cells expressing non-clonal TCRBV03-01 sequences. These findings support the model of Thorbecke et $\mathrm{al}^{4,5}$ but do not rule out the presence of small T-cell tumor clones. We conclude that a high proportion of SJL mice in our study developed lymphomas composed of transplantable, possibly clonal populations of B cells and frequent use of Trvb3 family members.

\section{Studies of Human AITL}

The features of SJL disease described above revealed certain parallels to AITL, a systemic malignancy of $\mathrm{T}_{\mathrm{FH}}$ frequently associated with clonal populations of B cells. The central role of IL-21 produced by $\mathrm{T}_{\mathrm{FH}}$ in SJL disease prompted us to examine its potential importance ${ }^{31}$ to AITL. To do this, we used Nanostring technology to test RNA prepared from formalin-fixed, paraffin-embedded sections of 40 cases of AITL using a panel of 45 probes (Supplemental Table S2). The characteristics of the AITL cases were similar to those reported in previous studies, ${ }^{20,32}$ with all having positive

Table 2 Age-Wise Tumor Incidence in Swiss Jim Lambart Mice

\begin{tabular}{lrlccc}
\hline Age, months & $N$ & DLBCL & PCT/APCT & HS & \% Tumors \\
\hline 2 & 4 & & & & 0 \\
3 & 5 & & & 0 \\
7.5 & 6 & 1 & & 17 \\
$9-10$ & 7 & 4 & & 57 \\
$11-12$ & 37 & 9 & 14 & 70 \\
15 & 4 & 1 & 1 & & 50 \\
$17-18$ & 9 & 2 & 2 & & 44 \\
$19-24$ & 8 & 1 & 4 & 3 & 100 \\
\hline
\end{tabular}

APCT, anaplastic plasmacytoma; DLBCL, diffuse large B-cell lymphoma; HS, histiocytic sarcoma; PCT, plasmacytoma. 


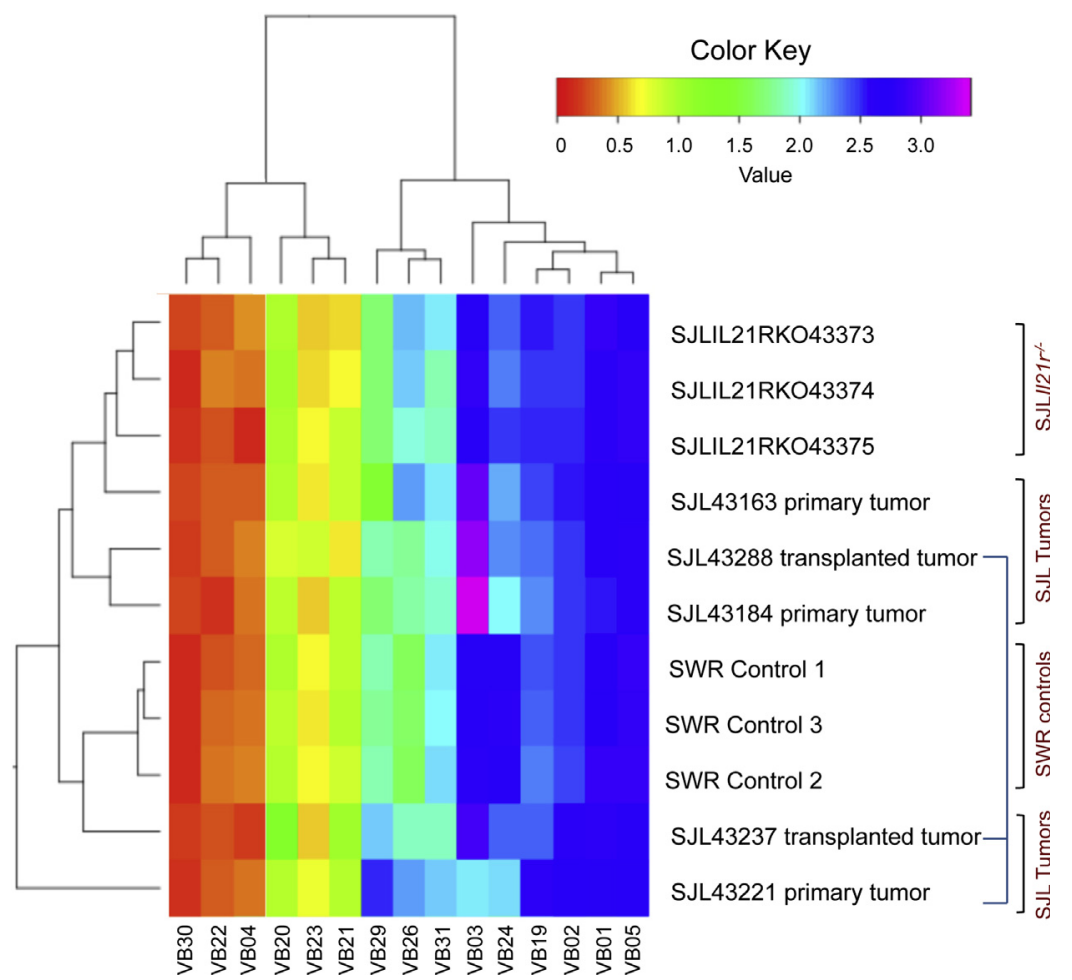

Figure 6 Characterization of T-cell receptor $\beta$ chain $(T c r b)$ use in primary and transplanted tumors from SJL mice. DNA prepared from primary SJL tumors, transplanted SJL tumors, SWR controls, and SJL.IL21R knockout (KO) mice was subjected to multiplex PCR with high-throughput sequencing and bioinformatics analysis. The heat map shows two-dimensional hierarchical clustering of the DNA sources and Tcrbv families. $n=3$ (primary SJL tumors, SWR controls, and SJL.IL21R K0 mice); $n=2$ (transplanted SJL tumors). Scale bar for expression levels is shown at the top.
EBV scores, almost all having clonal or oligoclonal rearrangements of T-cell receptor genes, and approximately $60 \%$ of those tested having clonal or oligoclonal rearrangements of $I g h$ or $\kappa$ light chain genes. The expression profile of the 45 RNA transcripts in AITL cases relative to control lymph node samples is shown in Figure 7. A subset of 14 genes was expressed at increased levels in the AITL samples with all but one, IL17A, having been recognized as overexpressed in earlier studies of AITL gene expression. ${ }^{9,10}$ Five of the eight most prominently overexpressed genes (IL21, IL21R, BATF, ILA, and ICOS) represent an interlocking signaling network that promotes the expression of IL-21 in $\mathrm{T}_{\mathrm{FH}}$ cells. The same cases were also analyzed using 33 probes directed more at T-cell genes and the common $\gamma$ chain cytokines and their receptors (Supplemental Table S2) but with considerable overlap with the genes shown in Figure 7. The only addition to the highly expressed genes identified in Figure 7 was IL15RA (data not shown). A significant number of cases also exhibited increased expression of STAT5 and JAK3 (data not shown), both of which are activated downstream of the IL-21R. None of the B-cell-associated genes tested exhibited increased expression when compared with expression in normal lymph nodes. These results may reflect the high level of these comparators in normal lymph nodes.

\section{Discussion}

The data presented herein showed that the diseases of SJL mice and humans with AITL have several features in common: i) adult presentation; ii) generalized lymphadenopathy with polymorphic cell populations, including plasma cells, histiocytes, and B-cell immunoblasts; iii) extranodal manifestations of splenomegaly and hepatomegaly; iv) polyclonal hypergammaglobulinemia frequently associated with clonal populations of B cells; v) expanded populations of $\mathrm{T}_{\mathrm{FH}}$; vi) high expression of IL-21 and its receptor; and vii) a uniformly lethal outcome.

Our new results, in combination with key earlier publications from Thorbecke et al, ${ }^{4,5}$ suggest a model for the pathogenesis of SJL disease that may have important implications for understanding AITL and, perhaps, for guiding new therapeutic modalities for the disease. There is strong support for critical involvement of a vSag encoded by a mammary tumor virus, Mtv29, in the development of SJL disease. Mtv29 vSag mRNA transcripts were detected in Peyer's patch B cells of 3to 6-month-old SJL mice, before the onset of lymphomas characteristic of this strain, but not in lymphoid tissues from other sites of age-matched SJL mice, including spleens and brachial lymph nodes. ${ }^{33}$ The Mtv29 vSag expressed in the context of $\mathrm{H}-2^{\mathrm{s}}$ on B cells stimulates the expansion of $\mathrm{CD} 4^{+}$ TRVB3 $\mathrm{T}$ cells, their differentiation to $\mathrm{T}_{\mathrm{FH}}$, and high-level secretion of IL-21. These $\mathrm{T}_{\mathrm{FH}}$ drive polyclonal B-cell activation, GC formation, and differentiation into class-switched Igsecreting cells. These cells exhibit remarkably high levels of Igh somatic hypermutation, indicating that they may have accumulated multiple mutations through repeated rounds of mutation and division, most likely in GCs. High-level expression of activation-induced (cytidine) deaminase, which is required for somatic hypermutation, can cause mutations in off-target genes that can contribute to 


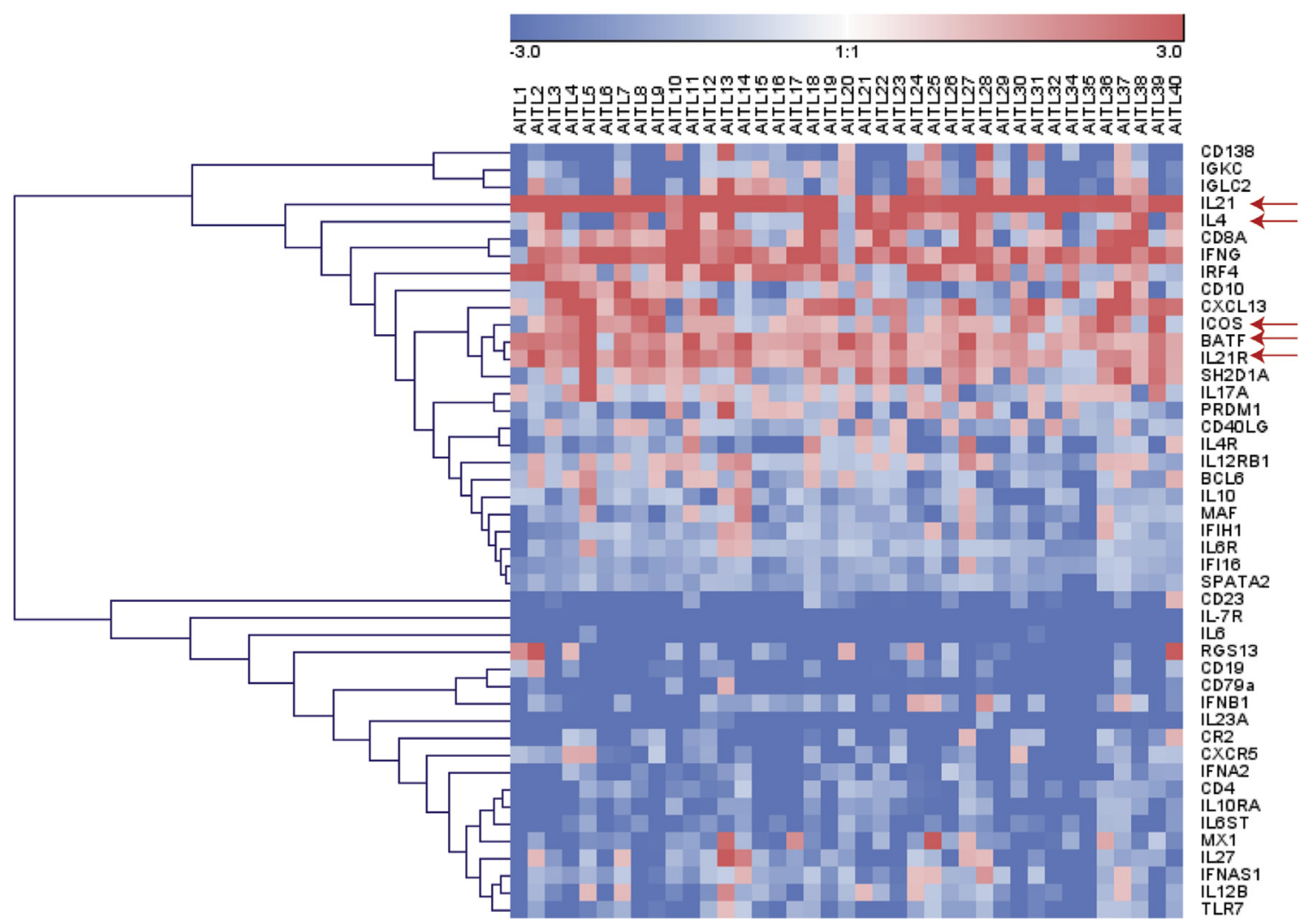

Figure 7 Human angioimmunoblastic T-cell lymphoma (AITL) cases exhibit enhanced expression of genes involved in the IL-21 signaling network. Transcript levels of 45 genes determined by Nanostring technology using RNA prepared from formalin-fixed, paraffin-embedded human AITL tissues. Hierarchical clustering analysis of all genes was performed, and the fold change of each gene in AITL samples over reference samples is shown in the heat map. Red arrows indicate five of the eight most prominent genes that promote the expression of IL-21 in T follicular helper cells. The bar at the top indicates the gene expression ratio relative to that of the control lymph node samples. $n=39$ AITL tissues. Scale bar $=-4$ to 4 .

transformation. $^{34,35}$ Our analyses of IL-21R-deficient SJL mice showed definitively that IL-21 signaling was absolutely required for essentially all disease manifestations that normally characterize SJL mice.

Clonal populations of B cells are also frequently found in AITL, but the defining tumor populations are $\mathrm{T}_{\mathrm{FH}^{-}}$-like $\mathrm{T}$ cells, ${ }^{10}$ with $95 \%$ of AITL cases containing clonal populations of T cells. It may be that the appearance of clonally transformed $\mathrm{T}$ cells is a late event in SJL disease of WT mice in contrast to AITL. This possibility is suggested by the observation that, although IL-21R-deficient SJL mice did not develop B-cell lineage lymphomas, several developed T-cell lymphomas at approximately 1 year of age. More important, the fact that the SJL neoplasms were lymphoblastic T-cell lymphomas clearly distinguishes them from the mature T-cell disease in AITL. Thus, it may be that WT SJL mice die of B-cell tumors before T-cell lymphomas can develop and that non-transformed $\mathrm{T}_{\mathrm{FH}}$-producing $\mathrm{IL}-21$, while continuously responding to Sags presented by B cells, is responsible for features resembling deranged immune or inflammatory responses, as seen in AITL. ${ }^{36}$

The mechanisms that might be responsible for $\mathrm{T}_{\mathrm{FH}}$ activation and expansion in human AITL are not known. In mice, $\mathrm{T}_{\mathrm{FH}}$ responses to T-dependent antigens are highly dependent on B cells for cognate and costimulatory signals. ${ }^{37}$ During the past 15 years, a series of superantigens encoded by human endogenous retroviruses have been identified in association with autoimmunity, infection, and malignancy. ${ }^{38-40}$ Although EBV has been postulated to play a role in disease, it does not express a

Table 3 Comparative Disease Features of SJL Mice and Human AITL Patients

\begin{tabular}{|c|c|c|}
\hline Features & SJL mice & AITL patients \\
\hline Increased $\mathrm{ICOS}^{+} \mathrm{PD}-1^{+} \mathrm{T}_{\mathrm{FH}}$ & + & + \\
\hline Increased IL-21 & + & + \\
\hline Clonal T cells & $-/+$ & $+/-$ \\
\hline Clonal B cells & $+/-$ & $-/+$ \\
\hline Viral antigens & Mtv29 vSAg & $\begin{array}{c}\text { Unclear; EBV-induced } \\
\text { HERV-K18 vSag }\end{array}$ \\
\hline FDC meshworks & - & + \\
\hline Expanded HEV & - & + \\
\hline $\begin{array}{l}\text { Mutations in IDH2, } \\
\text { TET2, RHOA, DMT3A }\end{array}$ & Unk & + \\
\hline $\begin{array}{l}\text { Mutations in } \mathrm{RC} 3 \mathrm{H} 1 \\
\text { (roquin) }\end{array}$ & - & - \\
\hline IL-21 dependence & + & Unk \\
\hline
\end{tabular}

AITL, angioimmunoblastic T-cell lymphoma; EBV, Epstein-Barr virus; FDC, follicular dendritic cell; HEV, high endothelial venule; ICOS, inducible T cell costimulator; Mtv, mouse mammary tumor virus; PD-1, programmed cell death protein 1; SJL, Swiss Jim Lambart; $T_{F H}$, T follicular helper; Unk, unknown; vSag, viral superantigen; +, positive; - , negative; +/-, both positive and negative cases. 
vSag. However, previous studies showed that EBV induces transcriptional activation of the Env gene of the endogenous retrovirus, HERV-K18, that encodes Sag activity. ${ }^{41}$ Expression of vSags may, therefore, represent another important tie between SJL disease and AITL.

It is interesting that expanding clones of $\mathrm{EBV}^{+} \mathrm{B}$ cells in AITL were found to exhibit extensive somatic hypermutation, resembling, to some extent, the features of $\operatorname{IgH}$ genes in SJL disease, ${ }^{32}$ and that cases associated with high circulating levels of EBV DNA were associated with impaired survival. ${ }^{42}$ An analysis of TRVB gene use in AITL, like that used in our study of SJL mice, would be helpful in determining if there is biased use of TRVB genes in this disease as well.

Our studies have identified a series of significant parallels between mouse SJL disease and human AITL (Table 3), with high expression of IL-21 associated with increased numbers of $\mathrm{T}_{\mathrm{FH}}$ being the most important. We emphasize this as interruption of IL-21 signaling inhibited the development of most manifestations of SJL disease. These findings could have major implications for therapeutic interventions in AITL.

Although we have focused on commonalities between AITL and SJL disease, it is important to note features that may distinguish the mouse and human diseases. Most prominent histologically may be the absence of expanded $\mathrm{CD} 23^{+}$follicular dendritic cell meshworks and prominent high endothelial venules in SJL disease. This could be a species-specific difference, but frequent loss of CD23 on follicular dendritic cells has been reported for $\mathrm{AITL}^{36}$ and antibody to CD23 was used in our studies in efforts to identify follicular dendritic cells.

Our findings with SJL mice provide major extensions to studies by Thorbecke et al. ${ }^{4,5}$ Their model for SJL disease was based on the observations that tumor growth in vivo and in vitro was dependent on $\mathrm{CD} 4^{+} \mathrm{T}$ cells and that $\mathrm{T}$-cell activity required the recognition on $\mathrm{B}$ cells of an antigen presented in the context of major histocompatibility complex class II molecules. This resulted in the secretion of cytokines, then poorly defined, that promoted tumor growth, a phenomenon they termed reverse immune surveillance. ${ }^{4}$ The responding $\mathrm{T}$ cells were enriched for those expressing TRBV3, allowing them to recognize a major histocompatibility complex class II-bound vSag expressed by tumors but not by most normal B cells. ${ }^{33,43-45}$ We have identified IL-21 as the critical cytokine driving SJL disease. The finding that several IL-21R-deficient 1-year-old SJL mice developed lymphomas, albeit of T-cell origin, indicates that expression of the vSag and IL-21 is not the entire story behind malignant transformation in this strain. Previous studies showed that SJL mice heterozygous for the $\mathrm{Fas}^{l p r}$ mutation exhibited accelerated B-cell tumor development compared with WT mice, although the mechanisms responsible for this phenotype were not determined. ${ }^{28} \mathrm{We}$ anticipate that studies of continuous cell lines derived from the tumors of WT mice will make it possible to identify these cooperating factors. Mice heterozygous for a mutation in the $R c 3 h l$ gene encoding roquin were reported to have clonal $\mathrm{T}_{\mathrm{FH}}$-related tumors and other similarities shared with
AITL. ${ }^{46}$ However, mutations in the homologous human gene were not found in AITL, ${ }^{47}$ and we did not find mutations by sequencing the SJL gene (data not shown).

On the basis of these parallels, we propose that SJL disease may provide a significant preclinical model for treatment of AITL with modalities that will block IL-21 effects at different points in its signaling pathway. An anti-IL-21R monoclonal antibody is in phase 1 clinical trials ${ }^{48}$ and trials of an IL-21-neutralizing antibody are planned. Anti-mouse antibodies with similar specificities have been generated and could be used to treat SJL disease. More important, findings with mice that are IL-21R deficient from birth do not provide information on whether disease progression can be blocked by inhibiting this pathway. The signaling pathway downstream of the IL-21R involves activation of Janus-activating kinase (JAK) 1 and JAK3 that signal activation of phospho-STAT3 and, to a lesser extent, STAT1 and STAT5. Inhibitors of JAK1 (ruxolitinib) and JAK3 (tofacitinib) are currently used for treatment of a range of disorders. In addition, JAK1 is a strong client of HSP90, ${ }^{49}$ and inhibition of HSP90 could add to the efficacy of JAK1 inhibition. ${ }^{50}$ In conclusion, we have extended the understandings of IL-21 effects in disease by demonstrating that $\mathrm{T}_{\mathrm{FH}}$ producing this cytokine are the driving force for reverse immune surveillance promoting the development of B-cell lymphomas of SJL mice and suggest this paradigm may extend to AITL.

\section{Acknowledgments}

This article is dedicated to the memories of Drs. Lloyd W. Law, Michael Potter, and Richard M. Asofsky, who introduced H.C.M. to SJL disease. We thank Val Bliskovsky (National Cancer Institute) for assistance with DNA sequencing.

\section{Supplemental Data}

Supplemental material for this article can be found at http://dx.doi.org/10.1016/j.ajpath.2015.07.021.

\section{References}

1. Murphy ED: Transplantation behavior of Hodgkin's-like reticulum cell neoplasms of strain SJL-J mice and results of tumor reinoculation. J Natl Cancer Inst 1969, 42:797-807

2. Stavnezer J, Lasky JL, Ponzio NM, Scheid MP, Thorbecke GJ: Reticulum cell sarcomas of SJL mice have rearranged immunoglobulin heavy and light chain genes. Eur J Immunol 1989, 19:1063-1069

3. Tang JC, Ho FC, Chan AC, Srivastava G: Clonality of lymphomas at multiple sites in SJL mice. Lab Invest 1998, 78:205-212

4. Thorbecke GJ, Ponzio NM: Reverse immune surveillance: an adaptive mechanism used by tumor cells to facilitate their survival and growth. Semin Cancer Biol 2000, 10:327-330

5. Ponzio NM, Thorbecke GJ: Requirement for reverse immune surveillance for the growth of germinal center-derived murine lymphomas. Semin Cancer Biol 2000, 10:331-340 
6. Crotty S: Follicular helper CD4 T cells (TFH). Annu Rev Immunol 2011, 29:621-663

7. Spolski R, Leonard WJ: IL-21 and $\mathrm{T}$ follicular helper cells. Int Immunol 2010, 22:7-12

8. Dunleavy K, Wilson WH, Jaffe ES: Angioimmunoblastic T cell lymphoma: pathobiological insights and clinical implications. Curr Opin Hematol 2007, 14:348-353

9. Iqbal J, Weisenburger DD, Greiner TC, Vose JM, McKeithan T, Kucuk C, Geng H, Deffenbacher K, Smith L, Dybkaer K, Nakamura S, Seto M, Delabie J, Berger F, Loong F, Au WY, Ko YH, Sng I, Armitage JO, Chan WC; International Peripheral TCLP: Molecular signatures to improve diagnosis in peripheral T-cell lymphoma and prognostication in angioimmunoblastic T-cell lymphoma. Blood 2010, 115:1026-1036

10. de Leval L, Rickman DS, Thielen C, Reynies A, Huang YL, Delsol G, Lamant L, Leroy K, Briere J, Molina T, Berger F, Gisselbrecht C, Xerri L, Gaulard P: The gene expression profile of nodal peripheral T-cell lymphoma demonstrates a molecular link between angioimmunoblastic T-cell lymphoma (AITL) and follicular helper T (TFH) cells. Blood 2007, 109:4952-4963

11. Federico M, Rudiger $T$, Bellei $M$, Nathwani BN, Luminari S, Coiffier B, Harris NL, Jaffe ES, Pileri SA, Savage KJ, Weisenburger DD, Armitage JO, Mounier N, Vose JM: Clinicopathologic characteristics of angioimmunoblastic T-cell lymphoma: analysis of the international peripheral T-cell lymphoma project. J Clin Oncol 2013, 31:240-246

12. Hartley JW, Chattopadhyay SK, Lander MR, Taddesse-Heath L, Naghashfar Z, Morse HC 3rd, Fredrickson TN: Accelerated appearance of multiple B cell lymphoma types in NFS/N mice congenic for ecotropic murine leukemia viruses. Lab Invest 2000, 80:159-169

13. Ozaki K, Spolski R, Feng CG, Qi CF, Cheng J, Sher A, Morse HC 3rd, Liu C, Schwartzberg PL, Leonard WJ: A critical role for IL-21 in regulating immunoglobulin production. Science 2002, 298:1630-1634

14. Shin DM, Shaffer DJ, Wang H, Roopenian DC, Morse HC 3rd: NOTCH is part of the transcriptional network regulating cell growth and survival in mouse plasmacytomas. Cancer Res 2008, 68:9202-9211

15. Vinuesa CG, Cook MC, Angelucci C, Athanasopoulos V, Rui L, Hill KM, Yu D, Domaschenz H, Whittle B, Lambe T, Roberts IS, Copley RR, Bell JI, Cornall RJ, Goodnow CC: A RING-type ubiquitin ligase family member required to repress follicular helper $\mathrm{T}$ cells and autoimmunity. Nature 2005, 435:452-458

16. Morse HC 3rd, Anver MR, Fredrickson TN, Haines DC, Harris AW, Harris NL, Jaffe ES, Kogan SC, MacLennan IC, Pattengale PK, Ward JM; Hematopathology Subcommittee of the Mouse Models of Human Cancers Consortium: Bethesda proposals for classification of lymphoid neoplasms in mice. Blood 2002, 100: $246-258$

17. Ward JM, Rehg JE, Morse HC 3rd: Differentiation of rodent immune and hematopoietic system reactive lesions from neoplasias. Toxicol Pathol 2012, 40:425-434

18. Johnson JL, Jones MB, Cobb BA: Polysaccharide A from the capsule of Bacteroides fragilis induces clonal CD4+ T cell expansion. J Biol Chem 2015, 290:5007-5014

19. Toivonen R, Arstila TP, Hanninen A: Islet-associated T-cell receptorbeta CDR sequence repertoire in prediabetic NOD mice reveals antigen-driven T-cell expansion and shared usage of VbetaJbeta TCR chains. Mol Immunol 2015, 64:127-135

20. Dudgeon C, Chan C, Kang W, Sun Y, Emerson R, Robins H, Levine AJ: The evolution of thymic lymphomas in p53 knockout mice. Genes Dev 2014, 28:2613-2620

21. Nicolae A, Pittaluga S, Venkataraman G, Vijnovich-Baron A, Xi L, Raffeld M, Jaffe ES: Peripheral T-cell lymphomas of follicular Thelper cell derivation with Hodgkin/Reed-Sternberg cells of B-cell lineage: both EBV-positive and EBV-negative variants exist. Am J Surg Pathol 2013, 37:816-826
22. Hao X, Fredrickson TN, Chattopadhyay SK, Han W, Qi CF, Wang Z, Ward JM, Hartley JW, Morse HC 3rd: The histopathologic and molecular basis for the diagnosis of histiocytic sarcoma and histiocyte-associated lymphoma of mice. Vet Pathol 2010, 47: 434-445

23. Cai G, Nie X, Zhang W, Wu B, Lin J, Wang H, Jiang C, Shen Q: A regulatory role for $\mathrm{IL}-10$ receptor signaling in development and $\mathrm{B}$ cell help of $\mathrm{T}$ follicular helper cells in mice. J Immunol 2012, 189: 1294-1302

24. Bansal G, DiVietro JA, Kuehn HS, Rao S, Nocka KH, Gilfillan AM, Druey KM: RGS13 controls g protein-coupled receptor-evoked responses of human mast cells. J Immunol 2008, $181: 7882-7890$

25. Shi GX, Harrison K, Wilson GL, Moratz C, Kehrl JH: RGS13 regulates germinal center B lymphocytes responsiveness to CXC chemokine ligand (CXCL)12 and CXCL13. J Immunol 2002, 169: $2507-2515$

26. Ramiscal RR, Vinuesa CG: T-cell subsets in the germinal center. Immunol Rev 2013, 252:146-155

27. McPhee CG, Sproule TJ, Shin DM, Bubier JA, Schott WH, Steinbuck MP, Avenesyan L, Morse HC 3rd, Roopenian DC: MHC class I family proteins retard systemic lupus erythematosus autoimmunity and B cell lymphomagenesis. J Immunol 2011, 187: $4695-4704$

28. Morse HC 3rd, Roths JB, Davidson WF, Langdon WY, Fredrickson TN, Hartley JW: Abnormalities induced by the mutant gene, lpr: patterns of disease and expression of murine leukemia viruses in SJL/J mice homozygous and heterozygous for lpr. J Exp Med 1985, 161:602-616

29. Jackson AM, Krangel MS: Allele-specific regulation of TCR beta variable gene segment chromatin structure. J Immunol 2005, 175: 5186-5191

30. Behlke MA, Chou HS, Huppi K, Loh DY: Murine T-cell receptor mutants with deletions of beta-chain variable region genes. Proc Natl Acad Sci U S A 1986, 83:767-771

31. Attygalle A, Al-Jehani R, Diss TC, Munson P, Liu H, Du MQ, Isaacson PG, Dogan A: Neoplastic T cells in angioimmunoblastic Tcell lymphoma express CD10. Blood 2002, 99:627-633

32. Brauninger A, Spieker T, Willenbrock K, Gaulard P, Wacker HH, Rajewsky K, Hansmann ML, Kuppers R: Survival and clonal expansion of mutating "forbidden" (immunoglobulin receptordeficient) Epstein-Barr virus-infected B cells in angioimmunoblastic T cell lymphoma. J Exp Med 2001, 194:927-940

33. Sen N, Simmons WJ, Thomas RM, Erianne G, Zhang DJ, Jaeggli NS, Huang C, Xiong X, Tsiagbe VK, Ponzio NM, Thorbecke GJ: METAcontrolled env-initiated transcripts encoding superantigens of murine Mtv29 and Mtv7 and their possible role in B cell lymphomagenesis. J Immunol 2001, 166:5422-5429

34. Duke JL, Liu M, Yaari G, Khalil AM, Tomayko MM, Shlomchik MJ, Schatz DG, Kleinstein SH: Multiple transcription factor binding sites predict AID targeting in non-Ig genes. J Immunol 2013, 190: $3878-3888$

35. Chiarle R, Zhang Y, Frock RL, Lewis SM, Molinie B, Ho YJ, Myers DR, Choi VW, Compagno M, Malkin DJ, Neuberg D, Monti S, Giallourakis CC, Gostissa M, Alt FW: Genome-wide translocation sequencing reveals mechanisms of chromosome breaks and rearrangements in B cells. Cell 2011, 147:107-119

36. Gaulard P, de Leval L: The microenvironment in T-cell lymphomas: emerging themes. Semin Cancer Biol 2014, 24:49-60

37. Nurieva RI, Chung Y, Hwang D, Yang XO, Kang HS, Ma L, Wang YH, Watowich SS, Jetten AM, Tian Q, Dong C: Generation of $\mathrm{T}$ follicular helper cells is mediated by interleukin-21 but independent of T helper 1, 2, or 17 cell lineages. Immunity 2008, 29: $138-149$

38. Holt MP, Shevach EM, Punkosdy GA: Endogenous mouse mammary tumor viruses (mtv): new roles for an old virus in cancer, infection, and immunity. Front Oncol 2013, 3:287 
39. Posnett DN, Yarilina AA: Sleeping with the enemy: endogenous superantigens in humans. Immunity 2001, 15:503-506

40. Stauffer Y, Marguerat S, Meylan F, Ucla C, Sutkowski N, Huber B, Pelet T, Conrad B: Interferon-alpha-induced endogenous superantigen: a model linking environment and autoimmunity. Immunity 2001, 15:591-601

41. Sutkowski N, Conrad B, Thorley-Lawson DA, Huber BT: EpsteinBarr virus transactivates the human endogenous retrovirus HERVK18 that encodes a superantigen. Immunity 2001, 15:579-589

42. Delfau-Larue MH, de Leval L, Joly B, Plonquet A, Challine D, Parrens M, Delmer A, Salles G, Morschhauser F, Delarue R, Brice P, Bouabdallah R, Casasnovas O, Tilly H, Gaulard P, Haioun C: Targeting intratumoral $\mathrm{B}$ cells with rituximab in addition to CHOP in angioimmunoblastic T-cell lymphoma: a clinicobiological study of the GELA. Haematologica 2012, 97:1594-1602

43. Katz IR, Chapman-Alexander J, Jacobson EB, Lerman SP, Thorbecke GJ: Growth of SJL/J-derived transplantable reticulum cell sarcoma as related to its ability to induce T-cell proliferation in the host, III: studies on thymectomized and congenitally athymic SJL mice. Cell Immunol 1981, 65:84-92

44. Lasky JL, Thorbecke GJ: Characterization and growth factor requirements of SJL lymphomas, II: interleukin 5 dependence of the in vitro cell line, cRCS-X, and influence of other cytokines. Eur J Immunol 1989, 19:365-371

45. Zhang DJ, Tsiagbe VK, Huang C, Thorbecke GJ: Control of endogenous mouse mammary tumor virus superantigen expression in
SJL lymphomas by a promoter within the env region. J Immunol 1996, 157:3510-3517

46. Ellyard JI, Chia T, Rodriguez-Pinilla SM, Martin JL, Hu X, NavarroGonzalez M, Garcia JF, Delfau-Larue MH, Montes-Moreno S, Gaulard P, Cook MC, Walters G, Piris MA, Vinuesa CG: Heterozygosity for Roquinsan leads to angioimmunoblastic T-cell lymphoma-like tumors in mice. Blood 2012, 120:812-821

47. Auguste T, Travert M, Tarte K, Ame-Thomas P, Artchounin C, Martin-Garcia N, de Reynies A, de Leval L, Gaulard P, DelfauLarue MH: ROQUIN/RC3H1 alterations are not found in angioimmunoblastic T-cell lymphoma. PLoS One 2013, 8:e64536

48. Hua F, Comer GM, Stockert L, Jin B, Nowak J, Pleasic-Williams S, Wunderlich D, Cheng J, Beebe JS: Anti-IL21 receptor monoclonal antibody (ATR-107): safety, pharmacokinetics, and pharmacodynamic evaluation in healthy volunteers: a phase I, first-in-human study. J Clin Pharmacol 2014, 54:14-22

49. Taipale M, Krykbaeva I, Koeva M, Kayatekin C, Westover KD, Karras GI, Lindquist S: Quantitative analysis of HSP90-client interactions reveals principles of substrate recognition. Cell 2012, 150: 987-1001

50. Marubayashi S, Koppikar P, Taldone T, Abdel-Wahab O, West N, Bhagwat N, Caldas-Lopes E, Ross KN, Gonen M, Gozman A, Ahn JH, Rodina A, Ouerfelli O, Yang G, Hedvat C, Bradner JE, Chiosis G, Levine RL: HSP90 is a therapeutic target in JAK2dependent myeloproliferative neoplasms in mice and humans. J Clin Invest 2010, 120:3578-3593 